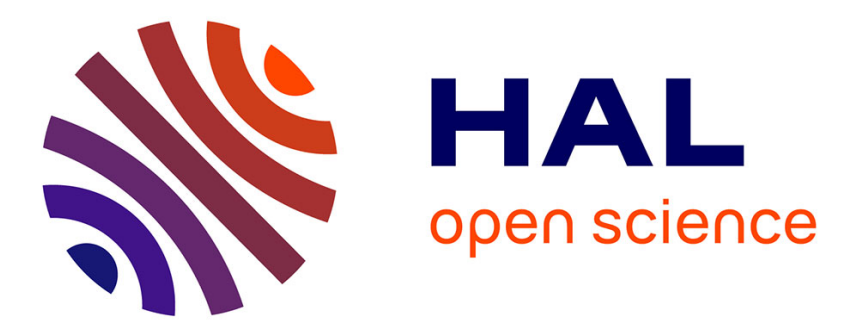

\title{
A coralline alga gains tolerance to ocean acidification over multiple generations of exposure
}

\author{
C. E Cornwall, S. Comeau, Q. D'alexis, T. M Decarlo, E. Larcombe, K.
} Giltrow, B. Moore, F. Puerzer, M. T Mcculloch

\section{- To cite this version:}

C. E Cornwall, S. Comeau, Q. D'alexis, T. M Decarlo, E. Larcombe, et al.. A coralline alga gains tolerance to ocean acidification over multiple generations of exposure. Nature Climate Change, 2020, 10 (2), pp.143-146. 10.1038/s41558-019-0681-8 . hal-03007123

HAL Id: hal-03007123

https://hal.science/hal-03007123

Submitted on 16 Nov 2020

HAL is a multi-disciplinary open access archive for the deposit and dissemination of scientific research documents, whether they are published or not. The documents may come from teaching and research institutions in France or abroad, or from public or private research centers.
L'archive ouverte pluridisciplinaire HAL, est destinée au dépôt et à la diffusion de documents scientifiques de niveau recherche, publiés ou non, émanant des établissements d'enseignement et de recherche français ou étrangers, des laboratoires publics ou privés. 
1 A coralline alga gains tolerance to ocean acidification over multiple generations of exposure 2 C. E. Cornwall ${ }^{1,2,3,{ }^{*} \dagger}$, S. Comeau ${ }^{1,2,4, \dagger}$, T. M. DeCarlo ${ }^{1,2}$, E. Larcombe ${ }^{1}$, B. Moore ${ }^{1}$, K.

3 Giltrow $^{1}$, F. Puerzer ${ }^{1}$, Q. D’Alexis ${ }^{1}$, M. T. McCulloch ${ }^{1,2}$

$4{ }^{1}$ Oceans Institute and Oceans Graduate School, The University of Western Australia, 35

5 Stirling Hwy, Crawley 6009, Australia.

$6 \quad{ }^{2}$ ARC Centre of Excellence for Coral Reef Studies, The University of Western Australia, 35

$7 \quad$ Stirling Hwy, Crawley 6009, Australia.

$8 \quad{ }^{3}$ School of Biological Sciences, Victoria University of Wellington, Wellington, New Zealand

9 4Sorbonne Université, CNRS-INSU, Laboratoire d'Océanographie de Villefranche, 181

10 chemin du Lazaret, F-06230 Villefranche-sur-mer, France

11 *For correspondence email: Christopher.cornwall@vuw.ac.nz

12 †These authors contributed equally

13 
14 Crustose coralline algae (CCA) play a crucial role in the building of reefs in the photic zones 15 of nearshore ecosystems globally and are highly susceptible to ocean acidification ${ }^{1-3}$. Yet the extent to which CCA can gain tolerance to ocean acidification over multiple generations of exposure is unknown. We show that while calcification of juvenile CCA is initially highly

18 sensitive to ocean acidification, after 6 generations of exposure the effects of ocean

19 acidification disappears. A reciprocal transplant experiment conducted on the $7^{\text {th }}$ generation

20 where half of all replicates were interchanged across treatments confirmed that they had acquired tolerance to low $\mathrm{pH}$ and not simply to laboratory conditions. Neither exposure to greater $\mathrm{pH}$ variability, nor chemical conditions within the micro-scale calcifying fluid internally, appeared to play a role in fostering this capacity. Our results demonstrate that reefaccreting taxa can gain tolerance to ocean acidification over multiple generations of exposure, suggesting that this cosmopolitan species could maintain its critical ecological role in reef-formation. 


\section{Introduction:}

A growing body of evidence suggests ocean acidification will greatly reduce the capacity of major reef-forming species to continue calcifying and hence to accrete the calcium carbonate building blocks of reefs ${ }^{2}$. CCA are ecologically important calcareous red macroalgae that help create and cement reefs from the tropics to the poles and provide a settlement substrate for marine invertebrate larvae such as corals, abalones and sea urchins. Coralline algae precipitate high magnesium calcite, one of the most soluble forms of calcium carbonate, and are therefore expected to be highly susceptible to increased dissolution rates under ocean acidification $^{4}$. Juvenile coralline algae are at particular risk, with extremely reduced abundance under ocean acidification ${ }^{5,6}$. Ocean acidification decreases both linear extension and calcification (hereafter termed growth) of CCA by altering the calcifying fluid chemistry of adult CCA to become less favorable for precipitation of calcium carbonate ${ }^{7-9}$. Adult coralline algae that are most resistant to ocean acidification tend to be those that can alter their mineralogy ${ }^{10}$ or resist changes to their calcifying fluid ${ }^{7-9}$.

It is currently unknown whether benthic calcifying organisms gain tolerance to ocean acidification after exposure for multiple generations. Our understanding of these processes in marine species is limited to either evolutionary responses of short-lived, non-reef-building species such as phytoplankton and non-calcareous polychaete worms over multiple (five to hundreds) generations ${ }^{11-13}$, or acclimatization responses of longer-lived species over 1 or 2 generations $^{14,15}$. Most reef-forming species have slower growth rates and generation times than microalgae, which has limited our ability to test whether they can gain tolerance to ocean acidification. However, some tropical reef-building and cementing CCA grow extremely fast to colonize available space after disturbance ${ }^{16}$, occupying a broad range of habitats that requires high phenotypic plasticity ${ }^{17}$. Some CCA also reproduce sexually or asexually within weeks of settlement, even while still microscopic ${ }^{18}$. These traits make CCA valuable model organisms to test whether reef-accreting calcifying species can potentially gain tolerance to ocean acidification over multiple generations of exposure.

In many shallow-water reef environments, night-time declines in $\mathrm{pH}$ due to local metabolic activity often exceed the changes in open-ocean $\mathrm{pH}$ predicted to occur by 2100 under business-as-usual $\mathrm{CO}_{2}$ emissions scenarios (e.g. Representative Concentration Pathway $8.5,0.4 \mathrm{pH}$ units $)^{7,20,21}$. It has been proposed that this natural diurnal variability may impart tolerance to low $\mathrm{pH}$ for resident calcifying species via selection for individuals that are better adapted to survive in these envrionments ${ }^{20,22}$. Additionally, transgenerational acclimation can occur via a variety of epigenetic or maternal effects after exposure of subsequent generations 
to stressors ${ }^{14,23}$, and could be promoted by prior exposure of individuals to greater variability in that stressor ${ }^{24}$.

We investigate whether the cosmopolitan reef-accreting and cementing species Hydrolithon reinboldii (synonymous with Hydrolithon boergesenii) can increase its tolerance to ocean acidification after multiple generations of exposure via mineralogical changes in skeletal formation or conversely the ability to resist seawater induced chemical changes to their calcifying fluid. We also test whether this tolerance can be gained faster in individuals with prior or regular exposure to low $\mathrm{pH}$. We grew $\mathrm{CCA}$ for 8 generations under present-day $(\mathrm{pH} 8.00)$ and future ocean acidification treatments $(\mathrm{pH} 7.70)$, with both high $( \pm 0.37)$ and low $( \pm 0.07) \mathrm{pH}$ variability, using populations from sites with either naturally low or high $\mathrm{pH}$ variability (see materials and methods and Table S1) and tracked complex changes in their calcification mechanisms. For the first time, we demonstrate that a species of coralline algae can gain tolerance to ocean acidification after 6 generations of exposure, but neither exposure to greater $\mathrm{pH}$ variability, nor changes in their calcification physiology related to mineralogy or chemistry in the calcifying fluid influence this capacity.

\section{Changes in sensitivity to ocean acidification}

The resistance of juvenile CCA to ocean acidification increased incrementally over each generation during this 423-day experiment. Second generation CCA grew 56.1\% slower across all ocean acidification treatments relative to the present-day treatments (Fig. 1). This sensitivity to lower mean $\mathrm{pH}$ declined over subsequent generations to 33.1, 29.7, 12.8, and $2.0 \%$ between generation 2 to 6 , supported by the significant interaction between mean $\mathrm{pH}$ and generation in the general linear model (Table $\left.\mathrm{S} 2, F_{1,224}=8.60, p=0.004\right)$. The difference further decreased to $0.6 \%$ when compared to the generation 7 populations kept in their original treatments (Fig. 2). 


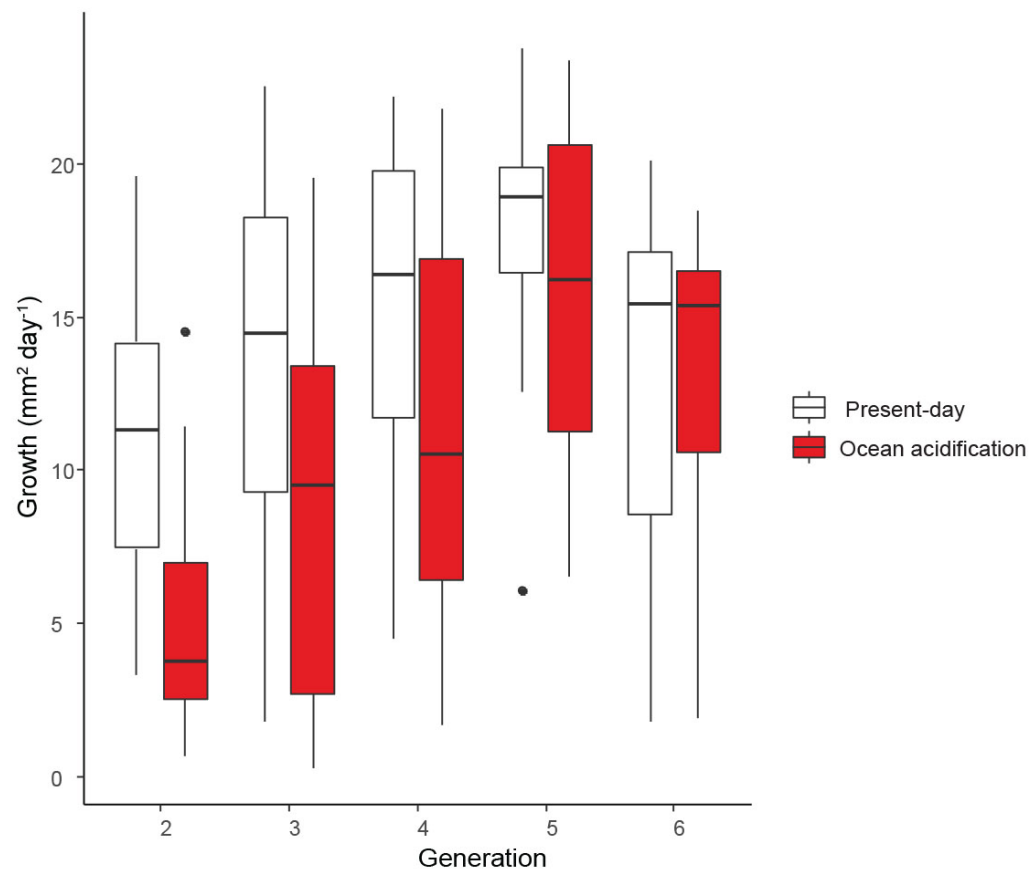

Median ocean

acidification

individual

Figure 1: Growth of CCA populations after 2 to 6 generations of exposure to present-day ( $\mathrm{pH}$ 8.00) and ocean acidification ( $\mathrm{pH} 7.70)$ treatments. Also shown are the median individual coralline algal plates for each generation under the ocean acidification treatments (out of 24). Scale 50 by $45 \mathrm{~mm}$ of images. Note here responses to constant and variable $\mathrm{pH}$ regimes combined. See supplementary figure Fig. S1 for individual treatment responses. Median and $75 \%$ quartiles, mean $n=24$ per treatment and generation combination.

\section{Reciprocal transplant experiment}

A reciprocal transplant experiment was also undertaken to test whether the CCA gained tolerance to ocean acidification rather than just the aquaria settings. This was undertaken at generation 7 where half of all replicates were interchanged with replicates of treatments with the opposite mean $\mathrm{pH}$ treatment, while keeping the variability the same as the previous generation (see methods). Growth was $40.3 \%$ lower in generation 7 populations transferred from the present-day into the ocean acidification treatments compared to those grown there for 6 generations, and this was $22.2 \%$ lower than the extension of control populations kept within the control treatments (Fig. 2, significant interaction between mean $\mathrm{pH}$ treatment and the treatment of origin: Table $\left.\mathrm{S} 3, F_{1,79}=4.6, p=0.035\right)$. The negative effects of low $\mathrm{pH}$ on growth were larger in populations originally from the more variable $\mathrm{pH}$ 
site compared to the stable $\mathrm{pH}$ site in early generations over the course of the experiment (Fig. S1, $F_{1,224}=4.05, p=0.045$ ). This is contrary to the hypothesis that individuals from more variable environments are more tolerant to ocean acidification, or that they gain this tolerance more rapidly over multiple generations. Trends in total recruit area typically mirrored those of growth rates, but were inherently more variable (Fig. S2, S3, Table S3-4).

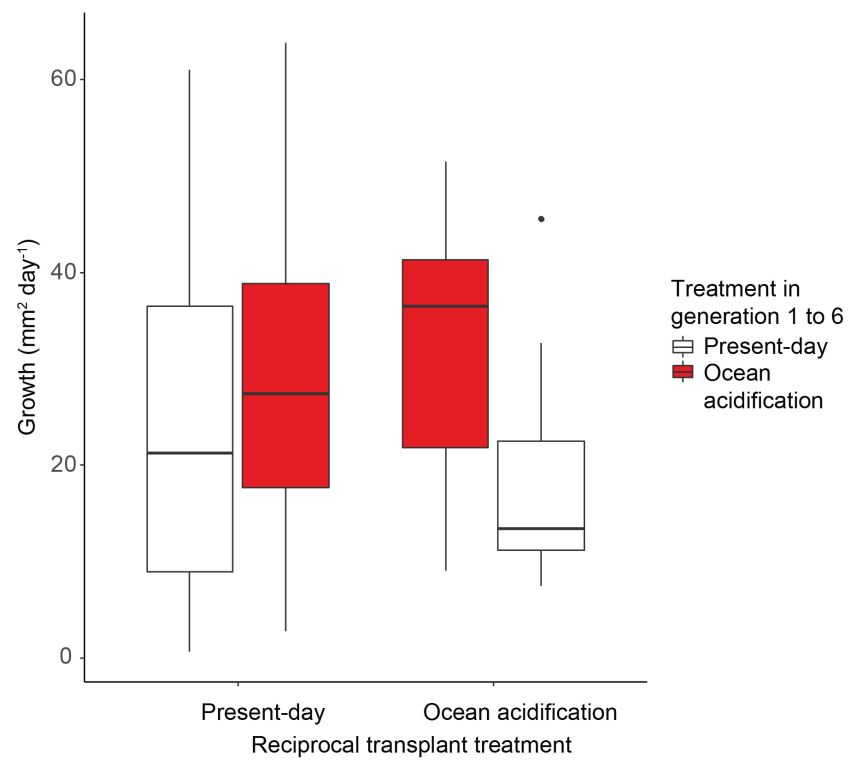

Figure 2: Growth of CCA after 7 generations grown in present-day $(\mathrm{pH} 8.00)$ and ocean acidification ( $\mathrm{pH} 7.70)$ treatments (controls), versus those transferred into these novel treatments after being in the treatment with the other mean $\mathrm{pH}$ for 6 generations. Responses to constant and variable $\mathrm{pH}$ regimes are combined. Median and $75 \%$ quartiles, $n=12 \mathrm{per}$ treatment and generation combination.

\section{Implications for future nearshore reefs}

This is the first demonstration that over multiple generations of exposure benthic calcifying species can increase their tolerance to ocean acidification, indicating that at least this species of CCA has the potential to gain tolerance to ocean acidification well within the timeframe of when its effects will manifest. Although this finding is by-itself critical to more accurately forecasting reef futures, outstanding questions remain, including the generality of this finding amongst other coralline algal species and in combination with other stressors such as ocean warming or in the presence of competitors that could be unaffected by ocean acidification. However, if coralline alga can develop resistance to ocean acidification over multiple generations of exposure, it is possible that other calcifying benthic species with 
similar calcification mechanisms ${ }^{9}$ could have the same capability. This information is crucial for coral reefs, for example, where many coral species are long-lived and experimentally testing their capacity to gain tolerance over multiple generations is logistically challenging, requiring years or decades of exposure to ocean acidification in controlled laboratory settings.

\section{Evolutionary and physiological mechanisms promoting tolerance}

The diminishing effect of ocean acidification on growth over each subsequent generation supports the premise that successive cohorts of CCA are subject to strong selection for resistance to ocean acidification, or that transgenerational acclimation occurred on individuals within each tank. We did not aim to determine the underlying evolutionary processes that could alter tolerance to ocean acidification. Previous research indicates that species can gain complete tolerance after a full generation of exposure to climate change stressors ${ }^{14}$. Our evidence indicates slower, more incremental increases in tolerance to climate change stressors could also occur in select taxa in the future. However, the trends observed here were also rapid in the context of evolutionary adaption. The rapid (less than two years), yet incremental, nature of these changes, and the predominately asexual reproduction, indicate that transgenerational acclimatory processes could have played a large role in inducing the changes observed. However, the effects of ocean acidification were particularly strong on the recruitment of the first generations of CCA, and because selective pressure is a combination of the effect size of the stressor selected against and the heritability of the trait, we cannot rule out that selection for individuals better able to calcify under these treatments occurred. While not our aim here, the next step is to further understand the contributions of genetic versus epigenetic processes that contribute to changing tolerance under climate change in reef-building and accreting species.

Regardless of the eco-evolutionary processes involved, exposure to greater variability in $\mathrm{pH}$ did not foster the capacity to gain tolerance to ocean acidification faster ${ }^{24}$. This is surprising given that organisms from these habitats tend to respond more positively to ocean acidification $^{22,25}$, and that phenotypic or transgenerational plasticity is predicted to be higher on these populations ${ }^{17,24}$. Therefore, transplanting organisms from highly variable $\mathrm{pH}$ environments into habitats with constant $\mathrm{pH}$ regimes, as has been suggested regarding ocean warming and temperature variability ${ }^{26}$, might not be a successful strategy to combat against ocean acidification. The CCA also did not alter their calcifying fluid toward conditions 
traditionally considered favorable for precipitation ${ }^{8}$. Hence, physiological mechanisms that allow for tolerance in adult CCA could have no bearing on their persistence in future reefs. The physiological mechanisms responsible for reduced sensitivity under the ocean acidification treatments are complex. Raman spectroscopy analyses indicated that changes in the mineralogy from high magnesium calcite into less readily dissolved polymorphs such as dolomite did not occur here (Table S5, Figure 3). Similarly, neither $\delta^{11} \mathrm{~B}$ ( $\mathrm{pH}_{\mathrm{cf}}$ proxy) or Raman full width at half maximum (FWHM: proxy of the calcite saturation state in the calcifying fluid $\left[\Omega_{\mathrm{cf}}\right]$ when precipitation occurs) were elevated in individuals kept for 8 generations under mean low $\mathrm{pH}$ compared to generation 2 individuals (Table S6, S7, Figure 3). In fact, both $\delta^{11} \mathrm{~B}$ and FWHM decreased between generations 1, 2 and then the experimental endpoint, and they tended to be lower in ocean acidification treatments generally. The physiological ability to maintain elevated $\mathrm{pH}_{\mathrm{cf}}$ or $\Omega_{\mathrm{cf}}$ under low $\mathrm{pH}$ in adult coralline algae and corals are traits related to resistance to ocean acidification, and we hypothesized a priori that any CCA here that gained resistance to ocean acidification would have done so via improving these traits. However, changes in these calcification-related parameters $\left(\delta^{11} \mathrm{~B}, \mathrm{FWHM}, \mathrm{Mg}\right)$ do not match changes in growth rates over successive generations under ocean acidification. The inverse relationship between FWHM and growth throughout the course of the experiment (Figure S5), together with lack of changes in other geochemical parameters, indicates that CCA tolerant to ocean acidification here were those which could calcify when carbonate chemistry is suboptimal for precipitation within the calcifying fluid, when compared to that of adults or controls. This is likely caused by both the rapid use of calcium and carbonate during calcification in the semi-enclosed space ${ }^{28}$, and declining $\mathrm{pH}_{\mathrm{cf}}$ via ocean acidification ${ }^{8}$. Additionally, traits such as increasing organic matrix proteins involved in calcification ${ }^{29}$ could also contribute to trends observed here.
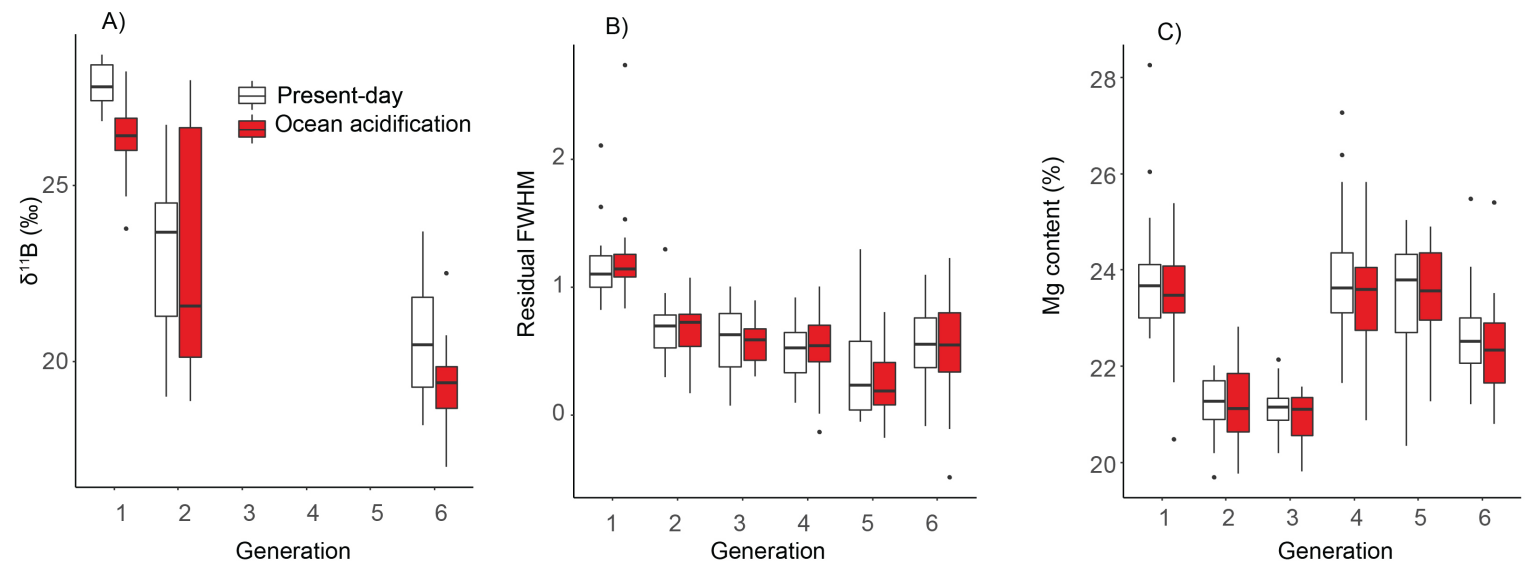
Figure 3: a) $\delta^{11} \mathrm{~B}$ (proxy for $\mathrm{pH}$ in the calcifying fluid), b) FWHM (proxy for calcite saturation state in the calcifying fluid), c) and $\mathrm{Mg}$ content of CCA over 6 generations under present-day or ocean acidification treatments. Median and 75\% quartiles, mean $n=24$ per treatment and generation combination.

\section{Conclusions}

These results highlight that we cannot predict which species will be winners or losers under climate change based solely on their responses to short-term exposure to acute stressors. We demonstrate for the first time that some coralline algae are capable of rapidly gaining tolerance to ocean acidification over six generations. If this capacity is present in other select species of coralline algae, then as a group they could be the largest contributors to global reef accretion in future oceans, given their already high abundance in temperate nearshore reefs, tolerance to ocean warming ${ }^{30}$, and the recent large-scale declines in the abundance of the longer-lived tropical scleractinian corals ${ }^{31}$.

\section{Methods}

\section{Collection and treatment design}

We collected adult coralline algae, Hydrolithon reinboldii (synonymous with boergesenii ${ }^{32}$ ), rhodoliths from Western Australia's northern Kimberley locations of Tallon (16 $40 \mathrm{~S}$, $\left.123^{\circ} 14 \mathrm{E}\right)$ and Shell Islands $\left(16^{\circ} 48 \mathrm{~S}, 123^{\circ} 04 \mathrm{E}\right)$ in October 2016 . These two sites are characterised by similar thermal regimes, but different $\mathrm{pH}$ regimes. Tallon Island is a seaweed and seagrass dominated reef with strong diel $\mathrm{pH}$ variability (up to 1.06 units daily). Shell Island is dominated by Acropora spp. corals and experiences a low range in $\mathrm{pH}$ variability (typically $<0.10$ units daily). This species was chosen because it is the most common species at both sites, and because it was the only species that lives at both sites that can be identified using morpho-anatomical methods, hence retaining intact and undamaged individuals that would not occur if molecular sequencing was required prior to the experiment starting. This species is common in the Indo-Pacific region ${ }^{33}$, and was identified with assistance by staff at the Western Australian Museum. Samples are lodged both at Victoria University of Wellington and the University of Western Australia. The collection, environmental variables at the collection sites, and experimental design and monitoring are described in detail within the initial segment of the research on the adults in Cornwall et al. ${ }^{7}$. Briefly, we created 4 treatments, within which each of the two source population were placed: 1) control means (8.00) and low $\mathrm{pH}$ variability (daily range of 0.14 ), or 2) high $\mathrm{pH}$ 
variability (0.58 daily range); 3) ocean acidification means (7.70) and low $\mathrm{pH}$ variability (0.20 range daily), or 4$)$ high $\mathrm{pH}$ variability (0.89 daily range). See Table $\mathrm{S} 1$ for full details, or Figure 1 from Cornwall et al. ${ }^{7}$ for schematic of details. There were 6 independent experimental tanks per treatment combination per population, for a total of 48 experimental tanks per generation. This allows us to determine the interactive effects of changes in both mean and variability in $\mathrm{pH}$. As recommended by all best practices guides ${ }^{34-37}$, we used $\mathrm{CO}_{2}$ gas to lower $\mathrm{pH} /$ elevate $\mathrm{CO}_{2}$ concentrations, and $\mathrm{CO}_{2}$-free air to increase $\mathrm{pH} /$ lower $\mathrm{CO}_{2}$. Seawater was pumped from an area of soft-sediment bottom 100m offshore at Watermans Bay, Perth, then filtered to $25 \mu \mathrm{m}$ using a series of sand filters, and then subsequently ran into a header tank where $\mathrm{pH}$ conditions were modified before moving into each experimental tank. There were 3 header tanks per treatment. Temperature was maintained in a series of waterbaths at 26 to $27^{\circ} \mathrm{C}, 4^{\circ} \mathrm{C}$ warmer than the summer maximum outside of our experimental facility. No recruitment of coralline algae occurred within this header tank, allowing us to be certain that coralline algal recruits throughout our experiment where not sourced from local populations. This temperature $\left(26\right.$ to $\left.27^{\circ} \mathrm{C}\right)$ roughly matches that of the collections site in the Kimberley region in $\mathrm{Winter}^{38}$ or is slightly higher, and was chosen to limit the stress that the CCA here would be exposed to. We chose to hold temperature constant during the duration of the experiment to avoid any confounding effects of temperature variations between generations.

\section{Multigenerational experiment}

On collection, only healthy adult coralline algae were selected that possessed extensive numbers of conceptacles (i.e. reproductive structures where spores are formed). On day 0 (i.e. the collection date), adult coralline algae were extensively cleaned of epiphytes and scrubbed to limit carry-over of other coralline algal spores from the field into the experimental set up. On day 78, coralline algal recruits were visible and on day 128 the adults were removed and the process of creating the generation 3 and subsequent generations began. This involved cutting out two 4.5 by $5 \mathrm{~cm}(\mathrm{~L} \times \mathrm{W})$ sections of the tank containing the highest cover of coralline algae recruits and placing these into completely new tanks, attached vertically (Fig. S7). Four of the generation 2 ocean acidification (both high and low variability) replicate tanks contained no visible recruits. For these tanks, populations from different tanks were used to create the third and subsequent generations. Therefore, we used 44 distinct populations of CCA to source the subsequent generations. We repeated this process once CCA recruits in the control treatment obtained the same estimated size as the $2^{\text {nd }}$ generation, 
roughly every 41 to 51 days. Once visible, CCA grew rapidly, approaching $1 \mathrm{~cm}$ diameter per week. The CCA on plates would then develop conceptacles and release spores which disperse into the water column around 2 weeks after being placed into brand new experimental tanks not previously used. A standardised size was used rather than a standardised time because of slight seasonal differences in the duration required to reproduce during each generation. This was process was continued until generation 7 . This resulted in using 336 separate experimental tanks $(7 \times 48)$ throughout the course of this study.

We acknowledge that it is possible that reproduction could be occurring in recruits even when microscopic (e.g. $\left.{ }^{18}\right)$, so in theory each generation could possibly be comprised of small amounts of differing generations. This would result in the number of generations here being more than the 8 recorded. However, we consider that extremely unlikely. This is because the experimental tanks were monitored daily, and we did not observe more rapid recruitment than would be expected if the recruits were reproducing before they became visible (i.e. weeks), or if time to reproductive maturity was variable, as recruits became visible in all tanks within the same weekly time frame when recruitment occurred. This consistent time to visible recruitment also means it was highly unlikely that recruitment occurred in generation 2 from spores of other species carried-over from the field. All coralline algal recruits possessed similar morphoanatomical features, including similarly sized and shaped conceptacles that aligned with the adults' identification ${ }^{39}$. Thousands of conceptacles were produced in each generation, and all that we analyzed contained multiple spores indicating that they were asexually reproducing ${ }^{40}$. Damaged conceptacles were not analyzed. In other words, the algae were asexually reproducing which is most common in coralline algae ${ }^{41}$, especially for this species for which only these life history stages have been noted ${ }^{39}$. The probability of skipping sexual reproduction in many species has previously been suggested ${ }^{41}$. A proportion of conceptacles were not fully formed at the end of each generation or their contents were already emptied or they were damaged, for these we cannot fully confirm the life stage or nature of reproduction.

We measured the linear extension of CCA on the created replicate plates using images taken every two weeks and analysed in ImageJ. This step involved analyzing 2496 images. We also assessed the total cover of recruits at the end of every generation. The trends in total area occupied by coralline algae in the tanks, and the growth on monitored plates were similar. However, it became apparent that the total area of recruitment was affected by both the treatment effect (mean $\mathrm{pH}$ ) on growth and random variability in the number of recruits. Therefore, we used the change in total area of the individuals of created plates as the focal 
measurement of interest, as it contained one response variable and not two (i.e. growth and recruitment success). See supplementary Figure 2 for these data, which follow similar trends but are inherently more variable. This step involved analyzing 1440 images. A random selection of more than $10 \%$ of all images were analyzed twice to check for consistency between multiple assessors.

\section{Reciprocal transplant experiment}

The process of exposing subsequent generations to their original treatment was continued in the 48 populations until generation 7, whereupon we conducted a reciprocal transplant to determine whether improved growth in ocean acidification treatments over time were representative of altered response to the treatments themselves, or an interaction between lab effects and altered response to treatments ${ }^{23}$. We exchanged half of the ocean acidification replicates with half of the ambient replicates within the same variability treatments, i.e. $\mathrm{pH}$ 7.70 low $\mathrm{pH}$ variability replicates interchanged with $\mathrm{pH} 8.00$ low $\mathrm{pH}$ variability replicates and vice versa. We did this because of the observed changing effects of mean $\mathrm{pH}$ over subsequent generations and lack of effects of $\mathrm{pH}$ variability. Therefore, we were not interested in the effects of switching individuals' treatments with differences in $\mathrm{pH}$ variability, only in how switching them between different mean $\mathrm{pH}$ treatments would influence fitness. When we create the additional novel or original treatments (i.e. "transferred" into novel treatments or placed in the same treatment as "controls") we have 16 different treatment combinations. We assessed growth over the first 2 weeks after transferring the generation 7 individuals into novel and control treatments, before they became limited for further space. We also measured total recruitment of their offspring after 61 days. We removed all standardised coralline algal plates from their tanks for the same length of time irrespective of whether they were transferred into a new treatment or placed into a control treatment.

\section{Measurement metrics}

We also measured proxies to aid in understanding changes in calcification physiology of the coralline algae at the completion of the experiment. $\delta^{11} \mathrm{~B}$, a proxy for $\mathrm{pH}$ at the site of calcification, was measured on generations 1,2,6,7 and 8 to determine trends over generations and due to treatments using previously published methods ${ }^{7-9}$, with the only 
difference being bleaching durations of 3 times as long. We also measured Raman spectroscopy on every generation as a proxy of the saturation state of calcium carbonate (based on $v_{1}$ Full Width at Half Maximum; FWHM) and magnesium content (based on $v_{1}$ wavenumber), following previously described protocols ${ }^{7,9}$.

\section{Statistical analysis}

We used general linear models in $\mathrm{R}$ to determine differences in growth, recruit area, and geochemical proxies across all available generations assessing the full interaction between mean $\mathrm{pH}$ (control or ocean acidification), $\mathrm{pH}$ variability (low or high), generations $(2,3,4,5$, 6), and site of origin (Shell or Tallon). Waterbath was used a random factor in models to account for this potential source of variability. For generations 7 and 8 , we used the same model structure, except the generation factor was replaced with the transfer (novel treatment or original control treatment) treatment and each generation was assessed separately, and waterbath was removed from the model. We used a log-fit mixed model for recruit area of generations 2 to 7 , due to non-normally distributed data.

\section{Data availability}

Data is available at dryad: https://doi.org/10.5061/dryad.pzgmsbcfq.

\section{Code availability}

All R code will be available upon request.

\section{Acknowledgments}

We thank A.-M. Nisumaa-Comeau and J.P. D'Olivo for laboratory assistance. V. Schoepf and S. McCoy for comments on a previous version. R. Townsend from the Western Australian Museum for training in species' identification. Funding: MTM was supported by an Australian Research Council (ARC) Laureate Fellowship. CEC, TMD and CEC by the ARC Centre of Excellence for Coral Reef Studies (CE140100020). SC was supported by an ARC Discovery Early Career Researcher Award (DE160100668). CEC was also supported by a Rutherford Discovery Fellowship from The Royal Society of New Zealand Te Apārangi (RDF-VUW1701). 


\section{Author contributions}

CEC and SC conceived and ran the experiment and wrote the manuscript. CEC ran the statistical analysis and conducted the boron isotope measurements. MTM conceived the experiment, provided vital laboratory equipment, facilities and resources. TMD conducted the Raman spectroscopy. EL, BM, KG, FP, and QD all ran the experiment and measured seawater carbonate chemistry. All authors edited the manuscript, provided intellectual input, and agreed to its submission.

\section{Conflicting interests}

We have no conflicts of interest.

\section{References:}

1 Nelson, W. A. Calcified macroalgae - critical to coastal ecosystems and vulnerable to change: A review. Marine and Freshwater Research 60, 787-801 (2009).

2 Kroeker, K. J. et al. Impacts of ocean acidification on marine organisms: quantifying sensitivities and interaction with warming. Global Change Biology 19, 1884-1896 (2013).

3 Heyward, A. \& Negri, A. Natural inducers for coral larval metamorphosis. Coral Reefs 18, 273-279 (1999).

4 Ries, J. B. Skeletal mineralogy in a high- $\mathrm{CO}_{2}$ world. Journal of Experimental Marine Biology and Ecology 403, 54-64 (2011).

5 Fabricius, K., Kluibenschedl, A., Harrington, L., Noonan, S. \& De'Ath, G. In situ changes of tropical crustose coralline algae along carbon dioxide gradients. Scientific reports 5, 9537, doi:10.1038/srep09537 (2015).

6 Ordoñez, A., Kennedy, E. V. \& Diaz-Pulido, G. Reduced spore germination explains sensitivity of reef-building algae to climate change stressors. PLOS ONE 12, e0189122, doi:10.1371/journal.pone.0189122 (2017).

7 Cornwall, C. E. et al. Resistance of corals and coralline algae to ocean acidification: physiological control of calcification under natural $\mathrm{pH}$ variability. Proceedings of the Royal Society B: Biological Sciences 285, doi:10.1098/rspb.2018.1168 (2018).

8 Cornwall, C. E., Comeau, S. \& McCulloch, M. T. Coralline algae elevate $\mathrm{pH}$ at the site of calcification under ocean acidification. Global Change Biology 23, 4245-4256 (2017).

9 Comeau, S., Cornwall, C. E., DeCarlo, T. M., Krieger, E. \& McCulloch, M. T. Similar controls on calcification under ocean acidification across unrelated coral reef taxa. Global Change Biology 24, 4857-4868, doi:10.1111/gcb.14379 (2018).

10 Nash, M. C. et al. Dolomite-rich coralline algae in reefs resist dissoltuion in acidified conditions. Nature Climate Change 3, 268-272 (2013).

11 Lohbeck, K. T., Riebesell, U. \& Reusch, T. B. H. Adaptive evolution of a key phytoplankton species to ocean acidification. Nature Geoscience 5, 346, doi:10.1038/ngeo1441 (2012). 
39712 Schlüter, L. et al. Adaptation of a globally important coccolithophore to ocean

398

399

400

401

402

403

404

405

406

407

408

409

410

411

412

413

414

415

416

417

418

419

420

421

422

423

424

425

426

427

428

429

430

431

432

433

434

435

436

437

438

439

440

441

442

443

444 warming and acidification. Nature Climate Change 4, 1024, doi:10.1038/nclimate2379 (2014).

13 Gibbin, E. M., Massamba N'Siala, G., Chakravarti, L. J., Jarrold, M. D. \& Calosi, P. The evolution of phenotypic plasticity under global change. Scientific Reports 7 , 17253, doi:10.1038/s41598-017-17554-0 (2017).

14 Donelson, J. M., Munday, P. L., McCormick, M. I. \& Pitcher, C. R. Rapid transgenerational acclimation of a tropical reef fish to climate change. Nature Climate Change 2, 30-32 (2012).

15 Putnam, H. M. \& Gates, R. D. Preconditioning in the reef-building coral Pocillopora damicornis and the potential for trans-generational acclimatization in coral larvae under future climate change conditions. Journal of experimental Biology 218, 23652372, doi:10.1242/jeb.123018 (2015).

16 Smale, D. A. \& Wernberg, T. Ecological observations associated with an anomalous warming event at the Houtman Abrolhos Islands, Western Australia. Coral Reefs 31, 441-441 (2012).

17 Boyd, P. W. et al. Biological responses to environmental heterogeneity under future ocean conditions. Global Change Biology 22, 2633-2650, doi:DOI:10.1111/gcb.13287 (2016).

18 Roleda, M. Y. et al. Effect of ocean acidification and $\mathrm{pH}$ fluctuations on the growth and development of coralline algal recruits, and an associated benthic algal assemblage. PLOS ONE 10, e0140394, doi:DOI:10.1371/journal.pone.0140394 (2015).

19 Rengefors, K., Kremp, A., Reusch, T. B. H. \& Wood, M. Genetic diversity and evolution in eukaryotic phytoplankton: revelations from population genetic studies. Journal of Plankton Research (2017).

20 Rivest, E. B., Comeau, S. \& Cornwall, C. E. The role of natural variability in shaping the response of coral reef organisms to climate change. Current Climate Change Reports 3, 271-281 (2017).

21 Anthony, K. R. N., A. Kleypas, J. \& Gattuso, J.-P. Coral reefs modify their seawater carbon chemistry - implications for impacts of ocean acidification. Global Change Biology 17, 3655-3666, doi:10.1111/j.1365-2486.2011.02510.x (2011).

22 Kapsenberg, L. \& Cyronak, T. Ocean acidification refugia in variable environments. Global Change Biology 0, doi:10.1111/gcb.14730 (2019).

23 Torda, G. et al. Rapid adaptive responses to climate change in corals. Nature Climate Change 7, 627, doi:10.1038/nclimate3374 (2017).

24 Donelson, J. M., Salinas, S., Munday, P. L. \& Shama, L. N. S. Transgenerational plasticity and climate change experiments: Where do we go from here? Global Change Biology 24, 13-34, doi:10.1111/gcb.13903 (2018).

25 Vargas, C. A. et al. Species-specific responses to ocean acidification should account for local adaptation and adaptive plasticity. Nature Ecology \& Evolution 1, 0084 (2017).

26 van Oppen, M. J. H., Oliver, J. K., Putnam, H. M. \& Gates, R. D. Building coral reef resilience through assisted evolution. Proceedings of the National Academy of Sciences 112, 2307-2313 (2015).

27 Gruber, R. K., Lowe, R. J. \& Falter, J. L. Metabolism of a tide-dominated reef platform subject to extreme diel temperature and oxygen variations. Limnology and Oceanography (2017). 
28 Ross, C. L., DeCarlo, T. M. \& McCulloch, M. T. Environmental and physiochemical controls on coral calcification along a latitudinal temperature gradient in Western Australia. Global Change Biology, doi:doi:10.1111/gcb.14488 (2018).

29 Mass, T. et al. Cloning and characterization of four novel coral acid-rich proteins that precipitate carbonates in vitro. Current Biology 23, 1126-1131 (2013).

30 Cornwall, C. E., Diaz-Pulido, G. \& Comeau, S. Impacts of Ocean Warming on Coralline Algal Calcification: Meta-Analysis, Knowledge Gaps, and Key

Recommendations for Future Research. Frontiers in Marine Science 6, doi:10.3389/fmars.2019.00186 (2019).

31 Hughes, T. P. et al. Global warming and recurrent mass bleaching of corals. Nature 543, 373, doi:10.1038/nature21707 (2017).

32 Rösler, A., Perfectti, F., Peña, V. \& Braga, J. C. Phylogenetic relationships of corallinaceae (Corallinales, Rhodophyta): taxonomic implications for reef-building corallines. Journal of Phycology 52, 412-431, doi:10.1111/jpy.12404 (2016).

33 Comeau, S. et al. Pacific-wide contrast highlights resistance of reef calcifiers to ocean acidification. Proceedings of the Royal Society B-Biological Sciences 281, doi:10.1098/rspb.2014.1339 (2014).

34 Gattuso, J. P., Gao, K., Lee, K., Rost, B. \& Schulz, K. G. in Guide to best practices for ocean acidification research and data reporting (eds U. Riebesell, V. J. Fabry, L. Hansson, \& J. P. Gattuso) Ch. 2, 41-51 (Publications Office of the European Union, 2010).

35 Hurd, C. L., Hepburn, C. D., Currie, K. I., Raven, J. A. \& Hunter, K. A. Testing methods of ocean acidification on algal metabolism: consideration for experimental designs. Journal of Phycology 45, 1236-1251 (2009).

36 Cornwall, C. E. \& Hurd, C. L. Experimental design in ocean acidification research: problems and solutions. ICES Journal of Marine Science 73, 572-581, doi:10.1093/icesjms/fsv118 (2015).

37 Barry, J. P., Hall-Spencer, J. M. \& Tyrrell, T. in Guide to best practices for ocean acidification research and data reporting (eds U. Riebesell, V. J. Fabry, L. Hansson, \& J. P. Gattuso) (Publications Office of the European Union, 2010).

38 Schoepf, V. et al. Stress-resistant corals may not acclimatize to ocean warming but maintain heat tolerance under cooler temperatures. Nature Communications 10, 4031, doi:10.1038/s41467-019-12065-0 (2019).

39 Townsend, R. A. \& Huisman, J. M. in Algae of Australia: Marine benthic algae of North-Western Australia Vol. 2 (ed J.M. Huisman) (CSIRO Publishing, 2018).

40 Harvey, A., Woelkerling, W., Farr, T., Neill, K. \& Nelson, W. Vol. 57145 p (NIWA Information Series, 2005).

41 Miklasz, K. A. Physical contrainsts on the size and shape on microalgae $\mathrm{PhD}$ thesis, Stanford University, (2012). 